\title{
Glycaemic indices of different varieties of rice grown in Sri Lanka
}

\author{
P Hettiarachchi', MTM Jiffry ${ }^{2}$, ER Jansz ${ }^{3}$, AR Wickramasinghe ${ }^{4}$ and DJS Fernando ${ }^{5}$
}

(Index words: Dietary advice, diabetes, obesity and ischaemic heart disease).

\begin{abstract}
Objective Varieties of red raw rice are widely believed to have a better nutritional quality. The physiological effects of consuming different varieties of rice may not be so. The glycaemic index has been developed as an indicator of the physiological effect of foods. It is the glycaemic response of a $50 \mathrm{~g}$ carbohydrate portion of food expressed as a percentage of that of a standard. The objective of this study was to determine the glycaemic indices of different varieties of rice grown in Sri Lanka.
\end{abstract}

Design Digestible carbohydrate content of 11 varieties of rice flour and bread were determined. Fasting blood samples followed by half-hourly samples for two hours were drawn after giving portions of either cooked rice or bread containing $50 \mathrm{~g}$ carbohydrate each.

Setting Fibre mill in Gampaha district.

Subjects Twenty-two fibre mill workers aged between 25 and 50 years.

Measurements The area under the blood glucose curve (AUC) for varieties of rice for a subject was calculated. Average AUC of 3 values for bread were calculated. Glycaemic index of each variety of rice was determined from the above variables.

Results Glycaemic indices of varieties of rice differ. The glycaemic indices of varieties of red raw rice varied between 56 and 73 and the variety $\mathrm{Bg} 350$ had the lowest glycaemic index. There was no significant difference between mean glycaemic index of varieties of white raw and some varieties of red raw rice $(p=0.2)$. Parboiled varieties of red raw rice had a significantly lower glycaemic index than white raw rice $(p=0.04)$ and some of the red raw rice $(\mathrm{p}=0.005)$.

Conclusions The glycaemic index cannot be predicted from the colour of the rice grain. Red parboiled varieties of rice and $\mathrm{Bg} 350$ can be recommended for patients with diabetes.

\section{Introduction}

Rice is the staple diet in Sri Lanka. We consume rice processed by different methods. The results of a recent survey carried out in Kandy district showed that a majority of consumers preferred varieties of red parboiled rice (1). Residents of southern coastal regions also preferred varieties of red raw rice, and those from urban areas preferred varieties of parboiled white rice (1). Varieties of red raw rice are popular among patients with diabetes. Nutritionists and medical professionals believe that red par- boiled varieties have a high non-starch polysaccharide (fibre) content.

The glycaemic index has been developed as an indicator of the physiological effect of foods (2). The glycaemic index indicates how rapidly the blood glucose will rise with different foods containing carbohydrate. Blood glucose raising ability of carbohydrates are compared against a standard food (white bread or glucose) and expressed as a percentage.

Low glycaemic index foods lead to lowering of the postprandial blood glucose level and produce a fall in the fructosamine and cholesterol levels in patients with type 2 diabetes (3). Low glycaemic index foods have been shown also to be beneficial in coronary heart disease (4). Insulin sensitivity and HDL concentration are two predictors of coronary heart disease that are influenced by the diet (4). There is a significant negative relationship between serum HDL concentration and glycaemic index of the diet. This suggests that inclusion of low glycaemic index foods in the diet will lead to a lower prevalence of coronary heart disease. Foods with low glycaemic index are useful in obesity (5) and sports medicine (6). Athletes should be encouraged to consume foods with low glycaemic indices 30 to 60 min before exercise as it will decrease the likelihood of hyperglycaemia and hyperinsulinaemia at the onset of exercise, and increase endurance time.

According to published reports different varieties of rice have variable glycaemic indices $(7,8)$. If the glycaemic index of a specific variety of rice is not known, advice given to patients with diabetes may not be evidence based. The selection of a variety of rice to be consumed by patients . with diabetes mellitus should be based on its physiological effects.

Methods

\section{Study sample}

Twenty-two volunteers of both sexes aged between 25 and 50 years with a normal glucose tolerance test participated in the study. Subjects were given a brief outline of the study and requested to report at $\mathbf{0 8 . 0 0}$ hours, after fasting for 12 hours on the assigned day. The University of Sri Jayawardenepura ethical committee approved the study.

\section{Blood collection}

Capillary blood was collected by finger-prick using sterile lancets. Eppendorf tubes containing the residue of sodium fluoride and potassium oxalate $(0.2 \mathrm{ml}$ solution containing $12 \mathrm{~g} / 100 \mathrm{ml}$ sodium fluoride and $1 \mathrm{~g} / 100 \mathrm{ml}$ potassium oxalate) were used for blood collection. After collecting

Departments of Physiology',2, Biochemistry ${ }^{3}$, Community Medicine and Family Medicine ${ }^{4}$, and Medicine ${ }^{5}$, Faculty of Medical Sciences, University of Sri Jayawardenepura. (Revised version accepted 20 January 2001. Financial support from National Science Foundation Grant RG/96/M/10). 
a fasting blood sample, each subject was given rice or bread containing $50 \mathrm{~g}$ carbohydrate (Table 1) with a spoonful of gravy and asked to consume the meal within $10 \mathrm{~min}$ utes. Water $(200 \mathrm{ml})$ was provided for drinking. Fingerprick blood samples were collected at 30, 60, 90 and 120 minute intervals after completion of the meal into Eppendorf tubes. An identified variety of rice or a standard food (bread) was fed at weekly intervals. The glucose oxidase method was used for blood glucose determination (9).

Table 1. Moisture content, digestible, carbohydrate content and weight of cooked rice and bread containing $50 \mathrm{~g}$ carbohydrates

\begin{tabular}{lccc} 
Rice variety & *Moisture & $\begin{array}{l}\text { \#Digestible } \\
\text { carbohydrate } \\
\text { content }(g)\end{array}$ & $\begin{array}{c}\text { Weights of portion } \\
\text { containing } 50 \mathrm{~g} \\
\text { carbohydrate }(\mathrm{g})\end{array}$ \\
Bw 302 & 65 & 66.5 & 215 \\
Bg 450 & 60 & 85.1 & 147 \\
Bg 94-1 & 65 & 75.2 & 190 \\
Bw 400 & 65 & 79.5 & 180 \\
Bw 272-6-B & 60 & 82.6 & 152 \\
Bw 351 & 65 & 73.5 & 195 \\
Bg & 60 & 72.8 & 172 \\
& & & \\
Bg 300 & 60 & 80.1 & 159 \\
Bg 94-1 & 68 & 59.9 & 261 \\
Bw 351 & 60 & 78 & 160 \\
Bw 272 6-B & 65 & 73.6 & 194 \\
Standard (bread) & 36 & 73.4 & 105 \\
\hline
\end{tabular}

(* Determined in $100 \mathrm{~g}$ of cooked rice. \# Values are expressed as percentage by mass on dry basis.)

\section{Rice}

Twelve different varieties of paddy were obtained from the Rice Research Development Institute, Batalagoda and Regional Agriculture Development Centre, Bombuwala (Table 2) Some of the samples of paddy were steam parboiled under standard conditions. Dehusking and milling of raw and parboiled varieties of rice were carried out at Rice Processing and Development Centre, Anuradhapura. The digestible carbohydrate content of rice flour and bread was determined by enzymatic hydrolysis (10) followed by Nelson's method (11). The moisture content of cooked rice and bread was calculated by the method of Dean and Stark (12). Using these data we prepared each portion of cooked rice and bread containing $50 \mathrm{~g}$ carbohydrate. The moisture content of cooked rice and bread was accounted for in this calculation (Table 1). Rice and bread portions containing $50 \mathrm{~g}$ carbohydrate were weighed using an electronic balance.

Table 2. Description of varieties of rice

\begin{tabular}{lcll}
$\begin{array}{l}\text { Rice breeding } \\
\text { Institution }\end{array}$ & $\begin{array}{l}\text { Method } \\
\text { of processing }\end{array}$ & $\begin{array}{l}\text { Rice } \\
\text { varieties }\end{array}$ & $\begin{array}{l}\text { Colour } \\
\text { of the } \\
\text { pericarp }\end{array}$ \\
Bathalagaoda & raw & $\begin{array}{l}\text { Bg 94-1 } \\
\text { wg 450 }\end{array}$ & $\begin{array}{l}\text { white } \\
\text { white } \\
\text { red }\end{array}$ \\
Bg 350 & Bg 94-1 & white \\
wathalagoda & parboiled & Bg 300 & white \\
& & Bw 302 & white \\
Bombuwala & raw & Bw 400 & red \\
& & Bw 272-6B & red \\
& & Bw 351 & red \\
& & Bw 272-6B & red \\
& & Bw 351 & red \\
\hline
\end{tabular}

\section{Bread}

White bread was prepared at the CISIR (Industrial Technology Institute) using a standard recipe. The same method was used throughout the study for preparation of bread.

\section{Gravy}

Gravy was prepared by adding garlic (Allium sativum) $(10 \mathrm{~g})$, spices $(10 \mathrm{~g})$, chillie powder (Capsicum frutescens) $(10 \mathrm{~g})$, goraka (Garcinia cambogia) (10 g) and salt to fresh Tuna fish (Neothunnus mactropterus) $(1 \mathrm{~g})$, and cooking in a large pot on low fire for one hour.

\section{Calculation of the glycaemic index}

Different curves were obtained for blood glucose values after different meals at $0,1 / 2,1,1 \frac{1}{2}$ and 2 hours. The area under the blood glucose curve (AUC) for a subject for a variety of rice was calculated (13). The AUC for rice and bread were calculated by applying the appropriate mathematical formula (13). The average of three AUC values of bread for a subject was obtained. The glycaemic index of a variety of rice for each subject was calculated using the formula shown below:

\section{AUC of test food \\ Glycaemic index $=\longrightarrow \times 100$ \\ AUC of reference food}

The glycaemic index of each variety of rice was found by taking the average of the above ratios. 


\section{Statistical analysis}

Content of carbohydrate and glycaemic indices of different varieties of rice were compared using the Student's $t$ test

\section{Results}

Digestible carbohydrate content of different varieties of rice varied from 74 to $84 \mathrm{~g} \%$. There was no difference between the digestible carbohydrate content of different varieties of rice.

The glycaemic indices of the varieties of rice under investigation are shown in Table 3. The glycaemic index of white rice ranged from 62 to 68 . The mean glycaemic index of varieties of parboiled white rice $(\mathrm{Bg} \mathrm{300,} \mathrm{Bg} 94-1)$ was 64 . The mean glycaemic indices of different varieties of raw white rice (Bg 450, Bg 94-1, Bw 302) was 66. The glycaemic indices of varieties of red rice varied from 56 to 73 . Bg 350, which is a raw red variety, had the lowest glycaemic index. The highest glycaemic index was observed in Bw 351, a raw red variety. The mean glycaemic index of all the varieties of raw red rice (Bw 400, Bw $272-6 \mathrm{~B}, \mathrm{Bw} 351, \mathrm{Bg} 350$ ) was 65 . The mean glycaemic index of varieties of parboiled red rice (Bw 272-6B, Bw351) was 57. The glycaemic indices of $\mathrm{Bg}$ 94-1 (68), Bw 272- 6B (68), Bw 351 (73), changed to 62, 58 and 56 respectively, followed parboiling $(p=0.04)$.

There was a significant difference in the mean glycaemic indices between varieties of parboiled red rice (Bw 272-6B, Bw351) and some varieties of raw red rice (Bw $400, B w 351, B w 272,6 B)(p=0.005)$, and raw white rice $(B g$ $450, B w 302, B g$ 94-1) ( $p=0.04)$. There was no significant difference between the mean glycaemic indices of varieties of parboiled white $(\mathrm{Bg} 94-1, \mathrm{Bg} 300)$ and varieties of parboiled red ( $B w 272-6 B, B w 351)$ rice $(p=0.09)$. No significant difference was observed between the mean glycaemic indices of parboiled white rice (Bg 94-1, Bg 300) and varieties of raw white (Bg 450, Bg 94-1, Bw 302) rice.

\section{Discussion}

The results of this study showed that glycaemic indices of different varieties of rice commonly consumed by Sri Lankans differ widely. Studies in other countries have also shown that there are wide variations in the glycaemic indices of different varieties of rice $(7,8)$. The glycaemic indices of varieties of red raw rice used in the present investigation varied between 56 and 73. This implies that the glycaemic index cannot be predicted from the colour of the rice grain. There were also no significant differences between the mean glycaemic indices of varieties of white raw and some of the red raw rice. Our results indicate that the colour of the rice grain is of little value in predicting its glycaemic index. Patients with diabetes, nutritionists and medical professionals believe that consuming varieties of red raw rice is better than white rice. The results of the present study show that all varieties of raw red rice do not have a low glycaemic index when compared to white rice. Only certain varieties of red parboiled rice and $\mathrm{Bg} 350$ can be specially recommended in obesity, patients with diabetes and with coronary heart disease. There is a need for formulating and implementing a policy on food labelling in Sri Lanka, so that consumers can easily obtain information about the glycaemic indices of different varieties of rice.

The parboiling process appears to lower the glycaemic index, especially of red raw rice, by changing in its physico-chemical properties. The effects of parboiling of red raw rice on the glycaemic index of raw red rice need further investigation.

Table 3. Glycaemic indices of varieties of rice

$\begin{array}{lllll}\text { Rice } & \text { Pericarp } & \text { Glycaemic index } & n & C V \\ \text { variety } & \text { colour } & \pm S E M & & \\ \text { Bg 450 } & \text { white } & 67 \pm 5 & 16 & 30.6 \\ \text { Bg 94-1 } & \text { white } & 68 \pm 6 & 16 & 37.1 \\ \text { Bw 302 } & \text { white } & 64 \pm 6 & 16 & 36.2 \\ \text { Bw 400 } & \text { red } & 66 \pm 5 & 15 & 27.5 \\ \text { Bw 2726-B } & \text { red } & 68 \pm 7 & 16 & 39.2 \\ \text { Bw 351 } & \text { red } & 73 \pm 4 & 19 & 24.9 \\ \text { Bg 350 } & \text { red } & 55 \pm 6 & 15 & 39.2 \\ \text { Bg 300 (parboiled } & \text { white } & 66 \pm 5 & 15 & 29.3 \\ \text { Bg 94-1 (parboiled) } & \text { white } & 62 \pm 6 & 15 & 38.0 \\ \text { Bw 351 (parboiled) } & \text { red } & 56 \pm 5 & 17 & 39.1 \\ \text { Bw 2726-B (parboiled) } & \text { red } & 58 \pm 5 & 22 & 42.9\end{array}$

(The glycaemic indices of white bread $=100 . n=$ number of subjects.) 


\section{Acknowledgements}

We thank the Rice Research Development Institute Bathalagoda, the Regional Agriculture Development Centre Bombuwala, for providing the required quantities of rice, the Rice Processing Research and Development Centre for dehusking and milling the rice and the CISIR (Industrial Technology Institute) for allowing us to use their laboratory for chemical analysis of rice. We are grateful to the National Science Foundation for funding this study.

\section{References}

1. Breckenridge C, Abesekera S, Hussein S, Nadesan MT. Survey to determine rice consumer preference in Kandy District. Tropical Agriculturist 1979; 135: 47-68.

2. Jenkins DJA, Wolever TMS, Taylor RH, Barker H, Fielden SRN, Bajdwin JM, et al. Glycaemic index of food: a physiological basis for carbohydrate exchange. American Journal of Clinical Nutrition 1981; 34: 362-6.

3. Frost G, Wilding J, Beecham J. Dietary advice based on the glycaemic index improves dietary profile and metabolic control in Type 2 diabetic patients. Diabetic Medicine 1994; 4: 397-401.

4. Frost G, Leeds AA, Dore CJ, Madeiros S, Dornhorst A. Glycaemic index as a determinant of serum HDL-cholestrol concentration. Lancet 1999; 353: 1045-48.

5. Slabber M, Bernard HC, Kuyl JM, Dannhauser A, Schall R. Effect of a low insulin response, energy restricted diet in weight loss and plasma insulin concentration hyperinsulinaemic obese females. American Journal of Clinical Nutrition 1994; 60: 4853.

6. Walton P, Rhodes EC. Glycaemic index and optimal sports performance. Sports Medicine 1997; 3: 164-72.

7. Miller JB, Pang E, Bramall L. Rice: a high or low glycaemic index food. American Journal of Clinical Nutrition 1992; 56: 1034-6.

8. Wolever TMS, Jenkins DJA, Kalmusky J, Jenkins A. Giordano C, Guidici S, et al. Comparison of regular and parboiled rice: explanation of discrepancies between glycaemic responses to rice. Nutrition Research 1986; 6: 349-57.

9. Hugget Ast G, Nixan DA. Use of glucose oxidase, peroxidase and dianisidine in the determination of blood glucose. Lancet 1952; 2: 368-70.

10. Pitipanarachchi RC. Industrial utilization of bread fruit (Artocarpus communis). MSc thesis. University of Sri Jayawardenepura, Nugegoda, Sri Lanka, 1997.

11. Nelson NA. Photometric adaptation of the Somogyi method for the determination of glucose. Journal of Biological Chemistry 1944; 153: 375-80.

12. Association of Official Analytical Chemist. Official Methods Analysis of the AOAC. 14 ${ }^{\text {th }}$ ed. AOAC, Washington, DC, 1984; 7: 4.

13. Wolever TMS, Jenkins DJA. The use of the glycaemic index in predicting the blood glucose response to mixed meals. American Journal of Clinical Nutrition 1986; 43: 167-72. 